\title{
LOS ARQUETIPOS DE LA SOMBRA, EL DOBLE Y EL AMOR ELUSIVO EN DETRÁS DEL ESPEJO DE JULIETA PINTO
}

\author{
The archetypes of the shadow, the double and the elusive love in \\ Detrás del espejo by Julieta Pinto
}

\section{Carlos Manuel Villalobos Villalobos *}

\begin{abstract}
RESUMEN
Esta comunicación, desde una perspectiva fundamentalmente junguiana, aborda el libro de cuentos Detrás del espejo de la escritora costarricense Julieta Pinto. En estos relatos se presenta un narrador íntimo que se busca a sí mismo y procura comunicarse con el otro. Sin embargo, este sujeto del deseo no consigue materializar la conexión amatoria, pues la presencia del arquetipo de la sombra se lo impide. A partir de este arquetipo, se genera un proceso de elusión amatoria, que se vincula con temas conexos tales como la soledad, la lejanía, la frialdad y lo ominoso. Como complemente de este escenario psicológico el texto presenta escenas oníricas que tienen lugar en un ambiente cargado de neblina. Esta condición impide que la imagen del espejo refleje con claridad a cada uno de los personajes.

Palabras clave: Julieta Pinto, literatura costarricense, novela costarricense, análisis junguiano.
\end{abstract}

\section{ABSTRACT}

This communication, basically from a Jungian perspective addresses the storybook Detrás del espejo by the Costa Rican writer Julieta Pinto. These stories present an intimate narrator that seeks into himself and tries to communicate with the other. However, this subject of desire fails to materialize the amatory connection, because the presence of the archetype of the shadow prevents it. From this archetype, it is generated a process of amatory avoidance, which is linked to related topics such as loneliness, remoteness, coldness and the ominous. As a complement of this psychological stage the text presents dream scenes that take place in a charged cloud environment. This condition prevents the mirror image clearly reflects each of the characters. Key Words: Julieta Pinto, Costa Rican Literature, Costa Rican novel, Jungian analysis.

* Universidad de Costa Rica. Profesor Escuela de Filología, Lingüística y Literatura. Costa Rica. Correo electrónico: carlos.villalobos@ucr.ac.cr

Recepción: 29/2/16. Aceptación: 10/4/16. 
¿Qué es real y qué pertenece al mundo de la imaginación? ¿Es posible que no haya una frontera clara entre el sueño y la vigilia? ¿Qué garantiza que las dimensiones de la conciencia no caminen por una banda de Moebius sin que nos percatemos de cuál lado es el real y cuál el imaginado? Estas dudas recurrentes en la historia del pensamiento humano, atraviesan el libro de cuentos Detrás del Espejo (2000) de la escritora costarricense Julieta Pinto.

Estamos frente a una obra que ubica a los personajes en el difuso límite entre los espacios supuestamente reales de la vigilia y los universos paralelos que crea el sueño. En este límite no hay respuestas que le permitan a la razón salir de la incertidumbre. Es por esto que en este nivel tienen lugar las preguntas existenciales, pero las explicaciones que se generan no son más que vacíos; o bien, un collage de atisbos que en principio parecen no tener coherencia. No es posible encontrar en esta dimensión anclajes de certeza. Aquí Eros y Tánatos parecen más bien un siamés unido por las eternas pulsiones del deseo. El sujeto que vive la experiencia de este ensueño, o estado difuso de la conciencia, camina a ciegas hacia lugares desconocidos. Los desenlaces de cada relato en vez de contribuir a resolver estas inquietudes más bien, en general, las agravan.

El libro está compuesto por diecinueve cuentos cortos y tienen como amarre conductor un narrador femenino en primera persona que experimenta distintas vivencias fantásticas y existenciales. Únicamente uno de los relatos está escrito en tercera persona y solamente en dos aparece un narrador masculino. Este sujeto femenino predominante es de edad madura, con trastornos neuróticos y recurrencias a memorias del pasado, principalmente relacionadas con el desamor.

En este trabajo nos centraremos en este sujeto femenino predominante. Para comprender las implicaciones de esta conciencia en crisis, el texto claramente contiene una clave que se vincula con de la exploración de la psique. Si partimos de esta premisa, el título Detrás del espejo, nos ofrece un amplio espectro semiótico para dar cuenta de las implicaciones psicológicas de estas mujeres, que en resumen son una misma.

Esta imagen que propone el título nos lleva, de entrada, a poner en escena un sujeto que reflexiona sobre sí mismo. En esta tarea el espejo tiene una larga tradición simbólica pues el sujeto, mediante el artilugio del reflejo, constata su propia existencia. Al adquirir conciencia de la imagen de sí mismo, al mismo tiempo se garantiza la identidad frente a otro. El espejo es un puente de significación entre el yo y el yo mismo; sin embargo, también puede ocurrir que este puente impida la fusión total de las imágenes y ocurra entonces un desdoblamiento: el yo frente a otro yo.

En el caso de estos cuentos de Julieta Pinto la mirada está puesta en la imagen que sucede detrás del espejo; es decir, se sugiere una separación. Esta condición conlleva a situaciones en las que se rompe el paso del yo al yo mismo y el sujeto se mira en el espejo sin asumirse plenamente. El yo frente al otro yo ocurre en cuentos como "La voz del río", donde la protagonista mira su cara en el espejo, se ve desencajada y con los ojos hundidos: "y no supe cuál era la ficción: la ciudad o yo. Quizás los amigos no me habían visto en el aeropuerto porque yo no existía" (25). El yo frente al otro yo en el espejo es mucho más evidente en el cuento "Desdémona", donde la protagonista narra lo siguiente: "Del espejo se desprende una figura arropada en un manto vaporoso, tan frágil que podría deshacerse en espuma. Su cara se parece mucho a mí, cuando era joven" (37).

Este espejo es el dispositivo simbólico del desdoblamiento. No devuelve un yo mismo, sino un posible yo otro. Volveremos más adelante sobre el tema del doble, pues en algunos de los relatos trasciende incluso el efecto de la mirada especular y se activa un Doppelgänger. Esta es la primera evidencia que explica la condición psicológica de estas protagonistas coincidentes: se resquebraja la certeza de la identidad y ocurre un enfrentamiento a una yo-otra.

Corresponde en este punto preguntarse qué marco teórico resulta apropiado para comprender estas fracturas de la psique. Desde luego que el psicoanálisis freudiano y 
el lacaniano nos ofrecen posibles herramientas. Sin embargo, calza también la tesis de que la construcción de este estado de la conciencia trasciende las dimensiones de la individualidad, como ya veremos, pues no estamos frente a una sola historia, sino frente a un collage de relatos con situaciones diferentes, aunque coincidan en el perfil general de las narradoras-protagonistas como un solo sujeto. Como huella plural de lo colectivo, este texto permite que los postulados clásicos de Karl Gustav Jung resulten útiles para comprender ciertos arquetipos que subyacen en estos relatos de Julieta Pinto.

De acuerdo con Jung, además de las experiencias personales de lo reprimido, en los rincones del inconsciente están instalados los mitos más antiguos de la memoria humana. En esta zona profunda estos mitos se reducen a signos primigenios llamados arquetipos. Según este reconocido psicólogo: "El inconsciente posee contenidos no sólo personales sino también impersonales, colectivos, en forma de categorías heredadas o arquetipos. De ahí nuestra hipótesis de que el inconsciente, en sus estratos en cierto modo más profundos, posee contenidos relativamente animados. Por eso hablo de un inconsciente colectivo" (1990:37).

Uno de los procedimientos recurrentes al aplicar los postulados junguianos a la literatura es la imposición a priori de los arquetipos. De acuerdo con Terrence Dawson, en muchos estudios literarios se utilizan los conceptos de Jung como si fueran categorías inmutables. Se imponen "dichos conceptos de modo esquemático a un texto determinado, bien interpretando un texto dado apelando a su afinidad con una interacción arquetípica cuyo significado se asume a priori. (1999: 356)

Esta trampa del apriorismo contradice la intención de Jung pues los arquetipos no son estructuras fijas. Cada cultura los actualiza y cada sujeto se vincula de cierta manera con algunas de las posibilidades.

Esta advertencia es importante para garantizar que el procedimiento que seguimos trasciende el apriorismo y procura una explicación con base en las huellas textuales que dictan los relatos.
Los trastornos a los que aluden los relatos de Julieta Pinto conectan, en efecto, con estas estructuras arquetípicas, pero no como un procedimiento mecánico o estático, a modo de anclaje final, sino como un proceso de atisbos que conectan y al mismo tiempo se desmarcan.

Como hemos dicho, la mirada en crisis frente al espejo implica la imposibilidad de mirar con claridad, por esta razón no es posible distinguir entre lo real y lo irreal. Este oscurecimiento es un leiv motiv presente en la mayoría de los relatos. Se materializa como neblina y no solo sucede frente al espejo, sino en otros escenarios en los que la protagonista no logra comprender lo que sucede.

Por ejemplo en el cuento "La voz del río", la neblina oculta el afluente que atraviesa la ciudad y hace enloquecer a la narradora. Cuando ella decide huir, la niebla impide que funcione el aeropuerto y de este modo la protagonista queda atrapada por la sombra.

La neblina aparece no solamente en espacios cerrados, como el cuarto o la iglesia, sino también en espacios abiertos, tal es caso de la montaña, como en el relato "El sortilegio" a donde la protagonista ha ido a suicidarse: "Desciendo de la montaña como si flotara entre la neblina y el fulgurante color de las orquídeas" (27). También aparece como textura de misterio en el encuentro fabuloso de la protagonista del cuento "Kutná Hora" con un héroe legendario; o bien, como mecanismo mágico de aislamiento, tal y como ocurre en el cuento "Las estrellas también hablan": "Caminé varios pasos, cuando una nube comenzó a opacar mi visión. Se extendió a mi alrededor y tuve la sensación de estar aislada, en un mundo vacío, sin ningún ser humano con quien pudiera comunicarme. No entendía aquel cambio brusco de un cielo sin nubes, a la llegada súbita de la niebla" (52).

En sus memorias, Jung confiesa que en un sueño enfrentó el descubrimiento de la sombra, y la definió como una condición oculta de sí mismo. La experiencia del descubrimiento presentaba como encuadre una densa bruma que lo cubría todo. De acuerdo con Jean Monbourquette, para Jung este descubrimiento 
lo lleva a plantearse lo que sería el primer arquetipo de su propuesta:

La sombra representa un conjunto de complejos, energías rechazadas, que Freud había denominado el "Ello". La sombra, tal como concebía Jung, se perfilaba desde siempre en los mitos y en las historias en forma de diversos arquetipos: la "hermana sombra", el "doble", los "gemelos"-uno de los cuales muestra un carácter siniestro-, el alter ego", etcétera (1999:26)

En el contexto de los relatos, tiene sentido entonces que la sombra se relacione con el espejo, pues se activa aquí, como hemos venido apuntando, un desdoblamiento que ocurre cuando la mirada no consigue ver con claridad el fondo. Este oscurecimiento que impide ver y explicar los hechos, funciona como indeterminación en la transición entre la realidad y lo onírico.

Otro de los cuentos en que aparece este arquetipo es en "Desafío del tiempo", donde la narradora se conecta con un desconocido a través de una pintura antigua. La imagen del cuadro le resulta inquietante y la cara del desconocido que la aborda en la sala de exposiciones es asombrosamente similar a la del cuadro. El hombre la invita a ir a un parque y ahí le manifiesta que la conoce desde siempre. Aquel hombre parece tener un ligamen eterno con la narradora. Resulta una presencia que evoca momentos gratos. Sin embargo, al final del cuento el acompañante desaparece sin dejar rastro:

Quiero hablar, decirle que nos aferremos a este presente, a este instante de pura alegría y la voz no brota. Quiero ampararme en sus brazos, pero la niebla se vuelve más densa y no veo su figura a mi lado. Permanezco inmóvil, arrebujada en la oscuridad del entorno. Cuando al fin se disipa la niebla, solo encuentro el arrullo de los pinos en el bosque humedecido. (14)

Obsérvese aquí como la niebla es la imagen que cubre la posibilidad de entender lo que sucede y tras esta sombra la presencia masculina desaparece. En consecuencia el abrazo que ella desea no es posible.

En este caso la sombra concuerda con uno de los temas recurrentes en el libro: la imposibilidad del amor o la crisis de pareja.
Esta situación se manifiesta de diversas maneras a lo largo de los relatos. En ocasiones la narradora evoca el recuerdo de un marido lejano, o bien de una presencia masculina que asfixia su libertad. Por ejemplo, en el cuento "El sortilegio" la narradora recuerda que se casó en plena adolescencia y "pronto me convertí en el ama de llaves de mi marido, la madre de sus hijos, la que calmaba su deseo. "No intenté separarme convencida de que él nunca me daría su divorcio" (27). Una situación similar ocurre en el relato "Lluvia" donde la narradora confiesa que "Evadí al hombre cada día pero hoy no hay excusa y mi cuerpo será fácil presa de su demanda" (45).

Esta misma dinámica de la masculinidad que ejerce un poder insano sobre la mujer, está presente en el motivo de "Desdémona" coincidente con el personaje que nos legó el canon literario gracias a la tragedia Otelo (1603) de Shakespeare. Recordemos que Desdémona era una mujer alegre y sensual y su esposo Otelo es convencido, equivocadamente, de que ella le es infiel. La tragedia de la obra consiste en que cegado por los celos Otelo acaba con la vida de su mujer. En el caso del cuento de Pinto, no hay un "feminicidio", pero la protagonista, quien es actriz, desea interpretar, sin éxito, el papel de este personaje de Shakespeare. El director de teatro le mata la posibilidad de ser. En la vida real, sin embargo, ella rompe el interdicto de la exclusividad: "Viví amores ajenos con tal intensidad que cuando el real, el que me arrolló en una avalancha de pasión y desasosiego se hizo presente, no supe distinguirlo de los demás y creí salir incólume como salía de cada una de las puestas en escena" (37-38).

Sin embargo, como se nota en esta cita, la marca del miedo de Desdémona está presente. Aparece el arquetípico de la sombra que persigue a la mujer. Por esta razón el personaje del cuento desea hablar, quiere "expresar esos vocablos atorados en mi garganta por los siglos, gritar mi derecho a la libertad" (40).

Este grito contenido, sin embargo, no aflora en estos relatos y esta parece ser la causa de la neurosis. En el cuento "Las estrellas también hablan", la protagonista hace un recuento de su 
vida y vincula su situación psicológica con un evento relacionado con su marido: "Las consecuencias de mi vida habían sido negativas, prueba de ello era la angustia, el insomnio de las noches, el ritmo acelerado de mi corazón al encontrar mi marido en una esquina" (49)

Como resultado de esta elusión amatoria, las protagonistas de los cuentos se caracterizan por una soledad que las agobia. Esta condición propicia, al mismo tiempo, la tendencia reiterada a imaginar más allá del borde de lo real. Esto lo reconoce la narradora del cuento "La voz del río" quien plantea: "No quiero dejarme llevar por el temor y continúo pensando en la posibilidad de que mi imaginación, exacerbada por la soledad, haya inventado todas esas fantasías" (26).

Esta soledad y la anulación del amor dan como resultado la frialdad en el sentido erótico. Este ausencia del ardor y la emoción amatoria, se proyectan también en los espacios; de ahí que la protagonista experimenta el frío de la montaña e igualmente las piedras de las paredes en la catedral se contagian de esta sensación: "Me acerco a la pared. Está fría, con la frialdad de las piedras que han soportado siglos de inmovilidad en su prisión" (35). Estas piedras cobran vida, tienen ojos brillantes: son también el reflejo de lo que vive la protagonista.

En la memoria de la narradora se advierten huellas de un pasado, a veces fantásticamente remoto y otras más recientes. En ese tiempo anterior, hay recuerdos de momentos gratificantes. Las caricias y la alegría pertenecen a este tiempo. Sin embargo, el fuego de la pasión ahora aparece apagado y queda solamente la nostalgia.

Frente a este sí mismo anulado una de las respuestas posibles es la huida, como puerta de salvación. En los cuentos esta evasión ocurre de diversas maneras. En primer lugar como acto de escape para librarse de una situación opresora. Por ejemplo, en el cuento "La voz del río" la desesperación de la protagonista la obliga a tomar una decisión: "No puedo continuar por esa ruta, tengo que huir" (25). No obstante, en este caso la neblina le impide cumplir con este cometido. Otro de los intentos de evasión es el suicidio. En el cuento "El sortilegio", la narradora cuenta que ha subido a una montaña para lanzarse al vacío, tal es el estado de depresión en se encuentra producto de su deteriorada relación con el marido llamado Carlos. Sin embargo, ocurre un hecho inusitado y en vez de morir decide desaparecer de otro modo: planea huir hacia otras tierras.

No todas las protagonistas tienen éxito en sus planes de evasión. La mayoría quedan atrapadas por la incertidumbre y la soledad. Pero de alguna manera, el límite entre la realidad y la ficción, la vigilia y lo onírico, resultan otro modo posible de escape; es decir, la no aceptación de la realidad tal cual y la imaginación de una realidad paralela. En el cuento "Solo el amor detiene el tiempo" la narradora plantea que "Al despertar me pregunto cuántas veces he tenido este sueño recurrente. No podría saberlo, pues no sé si es solo un sueño, o si mientras reposo en la oscuridad de la noche surgen escenas donde se unen realidad y fantasía y me es imposible distinguirlas" (29). Una situación similar ocurre con la protagonista de "Música del silencio": "Aquí existe la posibilidad de estar en un sueño que puede conducir a cualquier sitio desconocido y evaporar los muros para dar paso a la noche" (33). Esta condición alcanza un nivel hiperbólico en el cuento Sueño compartido, donde la nieta heredera de esta historia comparte el mismo sueño con la abuela: "El mundo de mis sueños ha crecido tanto que invade la vigilia sin pedir excusas por su intromisión" (43).

Lo onírico funciona como acceso al arquetipo de la sombra y es, al mismo tiempo, signo de la neurosis que viven las mujeres de estos relatos. Estos dos niveles se conectan como en una banda de Moebius, son el rostro frente al espejo y el rostro que se proyecta. Ahora bien, si la sombra es una energía rechazada que se materializa como lo siniestro, esto nos lleva a proponer que en este caso el arquetipo presenta una imagen primigenia de fuerte conexión simbólica.

Una de las características recurrentes de la sombra es una imagen zoomórfica que tiene la condición de reptar. Por ejemplo en el cuento "Música del silencio" la bruma de la Catedral es descrita de la siguiente manera: "La bruma 
de la tarde se destila por los vitrales arropando imágenes en mantos misteriosos. Las figuras se defienden de las miradas entre jirones de niebla, y veo solamente las sombras reptando desde la oscuridad" (33).

Esta imagen se repite en Desdémona, donde la neblina aparece en el cuarto de la protagonista y se describe del siguiente modo: "los objetos se diluyen en diseños extravagantes, nacidos de una luz difusa que en forma reptante ha invadido lo anteriormente presente" (37)

La serpiente como configuración arquetípica tiene múltiples atribuciones en las distintas culturas; sin embargo, si se considera el contexto occidental en el que se inscribe este libro, es posible precisar algunas consideraciones. Al respecto, en su Diccionario Ideológico Feminista (2000) la escritora Victoria Sau propone que la serpiente tradicionalmente es una figura relacionada con la tentación. Sin embargo:

La serpiente podría significar en el mito de la caída a la Gran Madre iniciadora de la hija, o sea, la relación madre-hija, la más arcaica y también la más prohibida, la que produce la auténtica filiación materna, la que es destruida y abolida por el patriarcado. EVA es el símbolo de esa destrucción.

En la díada madre-hija la maternidad no es una imposición y la sexualidad femenina está liberada. Por esto EVA es el símbolo de la sexualidad femenina reprimida y de la maternidad puesta al servicio del hombre. La serpiente es una representación de la mujer prepatriarcal:

En la figura de la serpiente al sexo femenino se le echa también la culpa del comercio sexual prohibido. Y así se levanta una barrera entre el sexo femenino simbolizado por la serpiente y un sexo femenino representado por EVA, ya sometido al dominio del varón. (2000:112)

Siguiendo esta tesis, la serpiente se convierte en lo reprimido y por lo tanto en imagen de la culpa instituida por el discurso patriarcal.

La sombra que subyace en este texto es el de la mujer anulada que quiere resurgir. Pero la presión social como discurso patriarcal se lo impide. Por esto mismo la imagen del espejo no se puede ver con nitidez. Es decir, frente al espejo está una mujer que acata los códigos exigidos según las reglas de la moral.

Pero en el fondo del espejo está la antigua deidad del deseo: la serpiente. Esta figura arquetípica no solo está en el fondo de la imagen que se refleja, forma parte del inconsciente colectivo y es la que tira de la mujer para recuperar su identidad arcaica. Recordemos que uno de los arquetipos tradicionales en el tema de lo femenino es la dicotomía entre la mujer ángel y la mujer demonio. El primero pertenece al mito mariano de la madre virginal y el segundo a los consabidos deleites eróticos de la mujer terrible, la Lilith del Génesis y sus ansias viperinas.

Esta mujer demonio, erótica y libre, tiene raíces arcaicas que afloran en la penumbra. En el cuento Pasado de Magia y sombras, la bruja regresa a celebrar este poder antiguo que goza en la clandestinidad: "Han pasado varios años dentro de mi normalidad cotidiana, pero ciertas noches, cuando brilla la luna con esa luz intensa del plenilunio, escapo de mi casa y corro hacia el claro del bosque donde me uno a la ceremonia que hace renacer mi pasado de magia y sombras" (72).

Es evidente que en las protagonistas de estos relatos lo que sucede es una ambigüedad entre ambos tipos: la bruja y la santa. Este límite conflictivo entre estas dos figuras antagónicas desde luego conduce a la locura. Recordemos, como prueba del desequilibrio psicológico, que algunas de las protagonistas confiesen que son adictas a las pastillas o bien que padecen de insomnio.

Una de las evidencias que corrobora esta dicotomía arquetípica es la presencia del doble. En el relato "Las estrellas también hablan", la protagonista ha ido donde un astrólogo y descubre que una mujer exactamente igual a ella hacía dos años también había ido. Corrobora que es ella misma pero no recuerda el hecho. El astrólogo no consigue explicar con certeza el futuro y la mujer se siente engañada. Al salir del consultorio se pierde en un mundo de brumas y mágicamente reaparece en su casa. Sin embargo, 
el Doppelgänger opera con más frecuencia en el contexto íntimo de ella frente al espejo, como ya comentamos.

\section{Algunas acotaciones finales}

Hasta aquí es posible constatar que las sombras a las que se accede en estos textos atisban estos posibles arquetipos con el sí mismo y el doble, como parte de la sombra. Sin embargo, estas configuraciones primitivas tienen otros elementos que van más allá y que configuran otros posibles arquetipos, entendidos siempre como marcas dinámicas que funcionan como hipótesis y no como certezas.

En el libro El temor al compromiso Steven Carter y Julia Sokol plantean que las dificultades de una relación no siempre tienen que ver con el otro. En muchos casos, el conflicto de pareja es solo la materialización de una situación propia que no se reconoce. (2002:45) Esta podría ser una tesis válida para explicar los casos que se exponen en los estos relatos.

De acuerdo con Carter y Sokol, las relaciones elusivas funcionas de dos maneras: el elusivo activo y el pasivo. El primero tiene una fobia declarada al compromiso y el segundo se asegura de vincularse emocionalmente con el primero, de modo que garantiza la imposibilidad de materializar la relación.

Las personas elusivas "Pueden sentir dolor, soledad, pueden ser infelices, pero ésa no es la cuestión. La cuestión es la muerte $y$, en un sentido, rechazar el crecimiento, el envejecimiento $y$, en última instancia, la muerte" (309).

Si bien, uno de los cuentos propone como salida el suicidio, en otros el tema aparece como un fantasma que acosa. Es el caso del relato "Un sueño compartido", donde la nieta sueña lo mismo que la abuela.

La imposibilidad de amar está determinada, desde luego, por la ambivalencia del doble. Mientras no se logre restablecer el equilibrio esta tarea no es fácil. Las pesadillas siguen acosando y la mujer cree que la persiguen los vampiros. La imagen es ominosa.
En ninguno de los cuentos hay una explicación posible. Como en un acto de magia, la transformación ocurre en unas condiciones que no permiten ver ni comprender lo que sucede. La duda se materializa como neblina, de este modo en cada caso se oculta, como en una cortina de humo, cualquier certeza o luz sobre los que pasa.

¿Quiénes son estos hombres que son y no son al mismo tiempo? ¿Qué es real y qué es un juego de la imaginación? ¿Qué es lo que subyace en esta conciencia que camina por el límite del sueño y la vigilia? Estas son las inquietudes sin respuesta que recorren este libro de relatos de la escritora de Julieta Pinto.

\section{Bibliografía}

Jung, Carl Gustav. 1990. Las relaciones entre el yo y el inconsciente. Trad. Julio Balderrama. Barcelona: Paidós.

Jung, C.G. 1963. Memories, Dreams, Reflexions. Panteon Books, New York.

Monbourquette, Jean. 1999. Reconciliarse con la propia sombra. El lado oscuro de la persona. Trad. Suso Ares Fondevila. Cantabria: Edición Sal Terrae.

Polly Young-Eisendrath y Terrence Dawson. Ed. 1999. Introducción a Jung. Trad. Silvia Horwath. Madrid: Cambridge University Press, Sucursal en España.

Pinto, Julieta. 2000. Detrás del espejo. Heredia: EUNA.

Sau, Victoria. 2000. Diccionario Ideológico Feminista. Volúmen I. 3ra Ed. Barcelona: Editorial Icaria

Carter, Steven y Sokol, Julia. 2002. El temor al compromiso. Trad. Adelaida Ruiz. Barcelona: Industrias Gráfica. S.A. 


\section{(2) $\Theta \Theta \Theta$}

Este obra está bajo una licencia de Creative Commons

Reconocimiento-NoComercial-SinObraDerivada 4.0 Internacional. 